\title{
Genome-wide identification and characterization of non- specific lipid transfer proteins in cabbage
}

\author{
Jialei Ji ${ }^{1}$ ， Honghao Lv ${ }^{1}$ ， Limei Yang ${ }^{\text {Corresp., }}{ }^{1}$ ， Zhiyuan Fang ${ }^{1}$ ， Mu Zhuang ${ }^{1}$, Yangyong Zhang ${ }^{1}$, Yumei Liu ${ }^{1}$, \\ Zhansheng Li ${ }^{1}$ \\ ${ }^{1}$ Key Laboratory of Biology and Genetic Improvement of Horticultural Crops, Ministry of Agriculture/Institute of Vegetables and Flowers, Chinese Academy \\ of Agricultural Sciences, Beijing, China
}

Corresponding Author: Limei Yang Email address: ylmcaas@163.com

Plant non-specific lipid transfer proteins (nsLTPs) are a group of small, secreted proteins that can reversibly bind and transport hydrophobic molecules. NsLTPs play an important role in plant development and resistance to stress. To date, little is known about the nSLTP family in cabbage. In this study, a total of 89 nsLTP genes were identified via comprehensive research on the cabbage genome. These cabbage nsLTPs were classified into six types (1, 2, C, D, E and G). The gene structure, physic al and chemical characteristics, homology, conserved motifs, subcellular localization, tertiary structure and phylogeny of the cabbage nsLTPs were comprehensively investigated. Spatial expression analysis revealed that most of the identified nsLTP genes were positively expressed in cabbage, and many of them exhibited patterns of differential and tissue-specific expression. The expression patterns of the nSLTP genes in response to biotic and abiotic stress es were also investigated. Numerous nsLTP genes in cabbage were found to be related to the resistance to stress. Moreover, the expression patterns of some nsLTP paralogs in cabbage showed evident divergence. This study promotes the understanding of nsLTPs characteristics in cabbage and lays the foundation for further functional studies investigating cabbage nsLTPs. 


\section{Genome-wide identification and characterization of 2 non-specific lipid transfer proteins in cabbage}

3 Jialei Ji ${ }^{1}{ }^{*}$, Honghao $\mathrm{Lv}^{1}{ }^{1 *}$, Limei Yang ${ }^{1}$, Zhiyuan Fang ${ }^{1}$, Mu Zhuang ${ }^{1}$, Yangyong Zhang ${ }^{1}$,

4 Yumei Liu ${ }^{1}$, Zhansheng $\mathrm{Li}^{1}$

5

$6 \quad{ }^{1}$ Key Laboratory of Biology and Genetic Improvement of Horticultural Crops, Ministry of

7 Agriculture/Institute of Vegetables and Flowers, Chinese Academy of Agricultural Sciences, No.

812 ZhongGuanCun South St., Beijing 100081, People's Republic of China

9

10 Corresponding author: Limei Yang

11 E-mail: ylmcaas@163.com

12 Tel: 0086-10-82108756; Fax: 0086-10-62174123

$13 *$ These authors contributed equally to this work. 


\section{ABSTRACT}

15 Plant non-specific lipid transfer proteins (nsLTPs) are a group of small, secreted proteins that can reversibly bind and transport hydrophobic molecules. NsLTPs play an important role in plant

17 development and resistance to stress. To date, little is known about the nsLTP family in cabbage.

18 In this study, a total of 89 nsLTP genes were identified via comprehensive research on the cabbage genome. These cabbage nsLTPs were classified into six types (1, 2, C, D, E and G). The gene structure, physical and chemical characteristics, homology, conserved motifs, subcellular localization, tertiary structure and phylogeny of the cabbage nsLTPs were comprehensively investigated. Spatial expression analysis revealed that most of the identified nsLTP genes were positively expressed in cabbage, and many of them exhibited patterns of differential and tissuespecific expression. The expression patterns of the nsLTP genes in response to biotic and abiotic stresses were also investigated. Numerous nsLTP genes in cabbage were found to be related to the resistance to stress. Moreover, the expression patterns of some nsLTP paralogs in cabbage showed evident divergence. This study promotes the understanding of nsLTPs characteristics in cabbage and lays the foundation for further functional studies investigating cabbage nsLTPs. 


\section{INTRODUCTION}

31 Non-specific lipid transfer proteins (nsLTPs), which are involved in binding and transporting various lipids, widely exist in the plant kingdom (Edstam et al., 2011). All known plant nsLTPs precursors include an N-terminal signal peptide, indicating nsLTPs are secreted proteins (Carvalho \& Gomes, 2007). The mature nsLTPs are small proteins characterized by an eightcysteine motif (8CM) with the basic form of C-Xn-C-Xn-CC-Xn-CXC-Xn-C-Xn-C (JoséEstanyol, Gomis-Rüth \& Puigdomènech, 2004). These eight cysteines are engaged in four disulfide bonds that stabilize the three-dimensional structure of the hydrophobic cavity, which allows the binding of different lipids and hydrophobic compounds (Douliez et al., 2000;

Salminen et al., 2016). Based on sequence similarity, the nsLTPs from Arabidopsis thaliana, rice, Solanaceae, and other plants are divided into ten types (I, II, III, IV, V, VI, VII, VIII, IX and X) (Boutrot, Chantret \& Gautier, 2008; Liu et al., 2010; Li et al., 2014). Recently, plant nsLTPs have been categorized into four major and several minor types by intron position, sequence identity and spacing between the cysteine residues in the $8 \mathrm{CM}$, as well as the post-translational modifications (Edstam et al., 2011; Salminen et al., 2016).

Plant nsLTPs are involved in multiple physiological functions, such as transport of cuticular lipids, cutin synthesis, cell wall extension, pollen development, pollen tube growth and guidance, stigma and pollen adhesion, plant signalling, biotic stresses, abiotic stresses, and seed maturation (Kader, 1996; Kiełbowiczmatuk, Rey \& Rorat, 2008; DeBono et al., 2009; Nieuwland et al., 2005; Safi et al., 2015). In addition, some plant nsLTPs have been identified as relevant allergens in plant foods and pollens (Liu et al., 2010). Moreover, plant nsLTPs display a complex tissue- 
51 specific and developmental expression pattern. NsLTPs are mainly expressed in the pericarp,

52 tapetum, epidermal cells of embryos, stems, leaves and roots (Zhang et al., 2008; DeBono et al.,

53 2009; Edstam et al., 2013). Interestingly, the expression of some $n s L T P S$ can be induced by

54 biotic and abiotic stresses, such as low or high temperature, drought, heavy metal exposure, and

55 disease (Jung, Kim \& Hwang, 2003; Gorjanović et al., 2004; Wu et al., 2004; Sun et al., 2008;

56 Saltzmann et al., 2010; Guo et al., 2013; Schweiger et al., 2013; Yu et al., 2014). The

57 overexpression of a barley nsLTP gene in transgenic Arabidopsis enhanced the tolerance of

Arabidopsis to bacterial pathogens (Molina \& García-Olmedo, 1997). In addition,

overexpression of a pepper nsLTP gene (CALTP1) in transgenic Arabidopsis could enhance the

resistance of Arabidopsis against infection by Pseudomonas syringae pv. tomato and Botrytis

cinerea and the tolerance of Arabidopsis to $\mathrm{NaCl}$ and drought stresses at various vegetative growth stages (Jung, Kim \& Hwang, 2005).

Cabbage (Brassica oleracea var. capitata) is an economically important vegetable which is

an important source of vitamin $\mathrm{C}$, vitamin $\mathrm{K}$ and other phytochemicals, such as sulforaphane and indole-3-carbinol (Wu et al., 2010; Ji et al., 2018). So far, information on cabbage nsLTP genes is lacking. The whole-genome sequence of B. oleracea var. capitata was completed in 2013 (Liu evolutionary patterns of the nsLTP family were investigated. Furthermore, we analysed the expression patterns of nsLTP genes in various cabbage organs. The expression patterns of the 
nsLTP genes in response to biotic and abiotic stresses were also investigated. These results lay a foundation for further analyses of nsLTPs functions and provide a framework for the utilization of nsLTP-encoding genes to breed cabbage with an increased quality and stress resistance.

\section{MATERIALS AND METHODS}

\section{Identification of cabbage nsLTP genes}

The entire cabbage proteome was downloaded from the B. oleracea database (Bolbase, http://www.ocri-genomics.org/bolbase). Proteins with the HMMPfam domain PF00234 (protease inhibitor/seed storage/LTP family) in the cabbage proteome were identified by using the software platform HMMER3 (Eddy, 2011). Moreover, BLASTP was also used to identify the cabbage nsLTPs. All known A. thaliana nsLTP sequences were obtained from The Arabidopsis Information Resource (TAIR, http://www.arabidopsis.org). These Arabidopsis sequences were then used as queries in a search against the cabbage protein database in Bolbase using BLASTP with the e-value $\leq 1 \mathrm{e}-3$. The newly identified cabbage nsLTP amino acid sequences were assessed via an analysis of the $8 \mathrm{CM}$ backbone. The proteins lacking essential cysteines were discarded.

\section{Amino-acid sequence analysis}

The signal peptide cleavage sites in the candidate nsLTP precursors were analysed by using the SignalP 4.1 program (Petersen et al., 2011). The proteins without N-terminal signal sequences (NSSs) were removed. The Arabidopsis protease inhibitor and storage protein sequences were used in a comparative analysis with the rest of the candidate nsLTPs to identify and discard potential protease inhibitors and storage proteins. The C-terminal glycosylphosphatidylinositol- 
93

94

95

96

97

98

99

100

101

102

103

104

105

106

107

108

109

110

111

112

113

anchored (GPI-anchored) signals in the candidate nsLTP proteins were analysed with the big-PI

Plant Predictor program (Eisenhaber et al., 2004). The subcellular localization of nsLTP was

predicted by TargetP 1.1 and Plant-PLoc server. After removing the signal peptide, the

theoretical isoelectric point $(\mathrm{pI})$ and molecular weight $(\mathrm{Mw})$ of mature nsLTP proteins were

calculated by the compute $\mathrm{pI} / \mathrm{Mw}$ tool provided in EXPASY

(http://web.expasy.org/compute_pi/). MEME software (v4.12.0) was used to search for motifs in all 89 cabbage nsLTP proteins, with a motif window length from 6 to 50 bp (Bailey et al., 2009).

The three-dimensional structures of the cabbage nsLTPs were constructed and analysed by

Phyre2 and PyMOL (Kelley et al., 2015).

\section{Orthologous analysis and chromosome localization}

The Arabidopsis nsLTP gene and protein sequences were used as queries in a BLAST search

against the cabbage genome and proteome database, with a coverage of $\geq 0.75$ and an e-value of

$\leq 1 \mathrm{e}-10$. The syntenic orthologous genes in cabbage and Arabidopsis were identified based on gene collinearity and sequence similarity (e-value $\leq 1 \mathrm{e}-20)$. All nsLTP genes were mapped to

the cabbage chromosomes based on the genome information obtained from Bolbase. The

chromosome localization map was made by using MapInspect software

(http://mapinspect.software.informer.com/).

\section{Alignment and phylogenetic analysis of nsLTPs}

The nsLTP proteins of Marchantia polymorpha, Physcomitrella patens, Selaginella

moellendorffii, Adiantum capillus-veneris, Pinus taeda, Oryza sativa, A. thaliana and B.

oleracea were aligned with MAFFT (v7.037) (Katoh \& Standley, 2013). Phylogenetic trees were 
114 115 116 117 118 119

constructed using FastTree (http://www.microbesonline.org/fasttree/) based on the WAG+CAT model (Price et al., 2009).

\section{RNA-seq data and bioinformatic analysis}

The expression levels of the nsLTP genes in seven different cabbage organs (root, callus, leaf, stem, bud, flower and silique) were investigated using RNA-seq data under the accession number GSE42891 in the Gene Expression Omnibus (GEO) database. The expression patterns of the nsLTP genes in response to low and high temperatures were analysed based on the RNA-seq data (ID: NN-0259-000003, NN-0259-000004, NN-0252-000006 and NN-0252-000003) from the National Agricultural Biotechnology Information Center (NABIC) (http://nabic.rda.go.kr/). An analysis of nsLTP gene expression in response to blackrot disease in disease-resistant and disease-susceptible cabbage was carried out based on RNA-seq data (SRA098802) from the NCBI Sequence Read Archive (SRA) database. RNA-Seq data (SRP091687) from male sterile/fertile buds was downloaded from the SRA database.

After the data processing of raw sequences, clean reads were aligned against the $B$. oleracea genome (http://www.ocri-genomics.org/bolbase/) using Tophat (v2.0.12). The transcript abundance of nsLTP genes was calculated by fragments per kilobase of exon model per million mapped reads (FPKM) or reads per kilobase per million mapped reads (RPKM). The differential gene expression analysis was performed using DESeq (v1.16). Genes with FDR-adjusted Pvalues $<0.05$ and fold-changes $>2$ were identified as differentially expressed genes (DEGs).

\section{RNA extraction and subcellular localization}

Total RNA from cabbage (line 02-12) leaves was isolated using the RNAprep Pure Plant Kit 
135 (TIANGEN) according to the manufacturer's instructions. Total RNA was reverse-transcribed 136 using the PrimeScript ${ }^{\mathrm{TM}}$ RT reagent kit (TaKaRa, Japan). The full coding sequences (CDSs) of 137 Bol014756 (BoLTP1.7) and Bol021902 (BoLTP2.3) were PCR-amplified with the primers PF1, 138 PR1, PF2 and PR2 (Table S1) and inserted into a pBWA(V)HS-GFP vector, resulting in an Nterminal fusion with GFP under the control of the constitutive CaMV35S promoter. The fusion constructs were introduced into tobacco leaf epidermis as previously described (Sparkes et al., 2006). The fluorescence signals were detected using the confocal laser-scanning microscope

142 (Nikon C1, Japan).

\section{RESULTS}

\section{Identification of the putative nsLTP genes in cabbage}

The nsLTP genes were identified by using the hmmsearch program in HMMER3 and a BLAST search against cabbage proteome. Initially, a total of 135 proteins with the conserved HMMPfam domain PF00234 were retrieved. The cysteine residue patterns of these protein sequences were then analysed. Fifteen proteins lacking the essential cysteine residues were omitted. After that, ten proteins lacking NSSs were also excluded (Table S2). Moreover, twelve proteins similar to protease inhibitors or storage proteins and nine hybrid proline-rich proteins were also discarded 151 (Table S2). As a result, a total of 89 nsLTPs, designated BoLTPs in this study, were identified in the cabbage genome (Table 1). Based on the orthology analysis, 74 BoLTP genes were found to have orthologous relationships with 42 A. thaliana nsLTP genes (Table 1). Among these orthologous genes, 49 BoLTP genes were syntenic orthologues of 27 A. thaliana nsLTP genes (Fig. 1A). 
157 The plant nsLTPs can be divided into four major and several minor types according to intron 158 position, sequence identity and spacing between the Cys residues in the $8 \mathrm{CM}$, as well as the posttranslational modifications (Edstam et al., 2011; Salminen et al., 2016). Based on the presence of a GPI modification site, the classification was initiated by first sorting the identified BoLTPs into Type G. In the second round of classification, the remaining BoLTPs were sorted based on the identity matrix calculated from the multiple sequence alignments. When compared with the classification proposed by Edstam et al. (2011) and Salminen et al. (2016), we found that 80 out of the 89 BoLTPs could be categorized into six types (1, 2, C, D, E and G). Type1, type2 typeD and type G nsLTPs, which encompassed 19, 12, 18 and 28 nsLTP genes, respectively, clearly represented a large proportion of the BoLTPs. Moreover, nine cabbage proteins displayed less BoLTPx1 to BoLTPx9 (Table 1). information in Bolbase. Sixty-eight (76.4\%) BoLTP genes were distributed across 9 chromosomes, and the rest were located on the unanchored scaffolds (Fig. 1B). Seven genes were located in chromosome 1 and 4, nine genes were located in chromosomes 2 and 8 , fifteen genes were located in chromosome 3, five genes were located in chromosome 5, 6 and 9, and six genes were located in chromosomes 7. In cabbage, seven direct repeat tandems consisting of 16 nsLTP genes were identified (Fig. 1B). One tandem of two duplicated nsLTP genes was presented in chromosome 1 (BoLTP1.6 and BoLTP1.7), chromosome 3 (BoLTPd13 and 
177 BoLTPd14), chromosome 4 (BoLTP1.13 and BoLTP1.14), chromosome 9 (BoLTPd17 and

178

179

180

181

182

183

184

185

186

187

188

189

190

191

192

193

194

195

196

197

BoLTPd18), and Scaffold000118_P2 (BoLTPx4 and BoLTPx5). One tandem of three duplicated

nsLTP genes was present in chromosome 2 (BoLTPd7, BoLTPd8 and BoLTPd9) and

chromosome 8 (BoLTPg7, BoLTPg8 and BoLTPg9).

\section{Characteristics of cabbage nsLTPs}

The characteristics of the 89 BoLTPs are summarized in Table 1. All the BoLTP protein

precursors possess a signal peptide of 17 to 34 amino acids. The putative subcellular localization

of BoLTPs was analysed. As expected, most of the proteins are predicted to be secreted except

for BoLTPe1, BoLTPg3 and BoLTPg26, which have been predicted to be chloroplast proteins

(Table 1). Except for type G nsLTPs, the Mws of the mature BoLTPs usually range from 6729

Da to 11906 Da, indicating the cabbage nsLTPs genes encode small proteins. Because the mature

nsLTPs of type $\mathrm{G}$ have more amino-acid residues in the C-terminus than the other mature

BoLTP proteins, they have much higher Mws (range from 12333.19 Da to 29369.39 Da). Among

the 89 BoLTPs, 57 display a basic pI (7.11-11.42) and the rest show an acidic pI (3.63-6.99). The

gene ontology categories of BoLTPs are shown in Fig. 1C.

To further analyse the characteristics of the BoLTPs, a multiple sequence alignment of

mature BoLTPs was conducted using MAFFT. Obviously, the eight-cysteine motifs of the 89

BoLTPs are conservative (Fig. S1). Moreover, the amino acid sequence alignment of the 8CMs

of BoLTPs reveals a variable number of inter-cysteine amino acid residues (Table 2). In order to

better understand the ligand binding and tertiary structure of BoLTPs, BoLTP1.5, BoLTP2.1 and

BoLTPd15 were selected as representative sequences of type 1,2 and D for structural modelling. 
198 199

200

201

202

203

204

205

206

207

208

209

210

211

212

213

214

215

216

217

218

The structural analysis showed that BoLTP1.5 includes two conserved pentapeptides, T-P-V-D-

R (positions 60-64) and P-Y-S-I-S (positions 100-104). It has been reported that these two

consensus pentapeptides (T/S-X-X-D-R/K and P-Y-X-I-S) play an important role in catalysis or

binding (Douliez et al., 2000). As shown in Fig. 2, the 3D structures of these three BoLTPs were

predicted and analysed by Phyre 2 and PyMOL. Each BoLTP possesses a compact $\alpha$-helical

domain consisting of four or five $\alpha$-helices connected by short loops (Fig. 2). Four disulfide

bonds formed by the eight-cysteine residues can stabilize the three-dimensional structure of the

hydrophobic cavity. In BoLTP1.5, the Cys residues 1-6, 2-3, 4-7, and 5-8 are paired (Fig. 2A),

whereas the Cys residues 1-5, 2-3, 4-7, and 6-8 are paired in BoLTP2.1 and BoLTPd15 (Fig. 2B,

C). This phenomenon indicated that the central residue of the $\mathrm{CXC}$ motif may influence the Cys

pairing and the overall fold of the protein. As shown in Fig. S1, the X position of CXC motif is

hydrophilic in type 1 BoLTPs. However, $\mathrm{X}$ is a hydrophobic residue in the CXC motif of Type 2

and Type D BoLTPs. Except for the disulfide bonds, many H-bonds also engage in the

stabilization of the three-dimensional structures of BoLTPs. The particular folding structure

forms an internal tunnel-like cavity that can bind different hydrophobic molecules.

\section{Phylogenetic analysis of the nsLTP family}

To analyse the phylogenetic relationship of the nsLTPs among $M$. polymorpha, $P$. patens, $S$.

moellendorffii, A. capillus-veneris, P. taeda, O. sativa, A. thaliana and B. oleracea, 187 nsLTPs

from these eight species were analysed (Table S3). These nsLTP sequences were aligned using

MAFFT (v7.037). Subsequently, the approximately-maximum-likelihood phylogenetic tree was

constructed from the multiple sequence alignment based on the WAG+CAT model. Previously, 
219 the plant nsLTPs have been divided into ten types (Edstam et al., 2011). Based on comparison

220 with the previous dataset, the six groups divided in this study were in agreement with the type 1,

221 2, C, D, E and G of nsLTPs. As shown in the phylogenetic tree, members in type 1, 2, C, and E

222 formed specific clades, suggesting that the nsLTPs in these types share a common ancestor (Fig.

223 3, Fig. S2). Although type D and G can be well distinguished from other types, they can not

224 formed separated clades (Fig. 3, Fig. S2). In particular the nsLTPs of type G were divided into

225 four subtypes (named G1 to G4) (Fig. 3). It was also worth noting that no type E nsLTP was

226 found in monocotyledon plants, which may discarded these genes during the evolutionary

227 divergence between monocots and dicots. Generally, A. thaliana and B. oleracea are closer to

228 each other and more distantly related to other species in each group of the phylogenetic tree,

229 indicating the closer relationship between A. thaliana and B. oleracea.

230 Expression analysis of nsLTP genes

231 To explore the spatial expression patterns of the BoLTP genes, RNA-Seq data from seven

232 different organs (root, stem, leaf, callus, bud, flower and silique) were used for an expression

233 analysis of BoLTPs. The expression level of each BoLTP gene was estimated by the FPKM

234 value, and the genes with FPKM $\geq 1$ were identified as truly expressed genes (Yao et al., 2015).

235 In this study, $72(81 \%)$ BoLTP genes were expressed in at least one of the seven organs (Fig. 4A,

236 Table S4). Interestingly, several BoLTP genes, such as BoLTP1.7, BoLTP1.10, BoLTP1.18,

237 BoLTP2.2, BoLTP2.12, and BoLTPx2, were specifically expressed in the buds. However, these

238 genes were significantly downregulated in the buds of $83121 \mathrm{~A}$, which is a male sterile mutant

239 with a defective exine (Fig. 4E, Table S5). 
To analyse the relationship between BoLTPs and cabbage resistance to biotic and abiotic

241

stress, comparative analyses of the expression of BoLTPs between the resistant and susceptible cabbage materials were conducted. Based on an analysis of RNA-Seq data from cabbage treated with cold stress for $2 \mathrm{~h}, 8$ BoLTPs demonstrated significant changes between the cold-tolerant BN10600 and cold-susceptible BN10700. Of these 8 DEGs, 6 were downregulated and 2 were upregulated in BN10700 (Fig. 4B, Table S5). Moreover, RNA-Seq data from two cabbage lines, heat-tolerant BN1HS and heat-susceptible BN2HS, that had been treated by heat shock for $1 \mathrm{~h}$, were used to explore the responses of BoLTP genes to high temperature. As shown in Fig. 4C, 7 DEGs were identified between BN1HS and BN2HS (Table S5). Of these DEGs, 5 were downregulated and 2 were upregulated in BN2HS. Black rot caused by Xanthomonas campestris pv. campestris is a major disease of cabbage. In order to explore the black rot resistance genes in cabbage, the differential expression analysis between the two cabbage parental lines, C1234, which is black rot disease-resistant and $\mathrm{C} 1184$, which is a susceptible line, were also carried out. According to Fig. 4D, 7 DEGs were identified between C1234 and C1184 (Table S5). Of these DEGs, 3 were downregulated and 4 were upregulated in C1184. Significantly, among these DEGs, 4 BoLTPs $(1.6,1.8, \mathrm{~d} 2$, and d11) DEGs may be related to the resistance to at least 2 types of stress.

The alteration of expression patterns is considered an important indicator of functional divergence between duplicated genes (Makova \& Li, 2003; Ganko, Meyers \& Vision, 2007; Hellsten et al., 2007). The differential expression analysis of the duplicated BoLTPs indicated significant expression differentiation among the paralogous BoLTPs (Fig. 5). For example, 
BoLTP1.1, BoLTP1.6 and BoLTP1.7 are orthologous to AT3G51590, which is known to be

262

involved in sexual reproduction in A. thaliana (Ariizumi et al., 2002; Chae et al., 2009).

BoLTP1.1 and BoLTP1.7 were mainly expressed in the floral organs, while BoLTP1.6 was

mainly expressed in the leaves and significantly upregulated in the blackrot disease-resistant C1234 (Fig. 4D, Fig. 5). As another example, BoLTPd7, BoLTPd8, BoLTPd9, BoLTPd12 and BoLTPd13 are orthologous to AT5G55450, which is involved in disease resistance in A. thaliana (Mclaughlin et al., 2015). BoLTPd7 was expressed in every investigated organ, BoLTPd8, BoLTPd 9 and BoLTPd13 were not expressed in any of the investigated organs, while BoLTPd12 was expressed in every investigated organ except the root. Moreover, BoLTPd7 and BoLTPd8 responded to cold and heat stress, but their responses to the stresses were opposite (Fig. 4C and D). BoLTPd9 responded to cold stress and was downregulated in the cold-susceptible BN10700 (Fig. 4C). These results indicate that the duplicated genes with different expression patterns may possess different physiological functions.

\section{DISCUSSION}

In this study, 89 genes putatively encoding nsLTPs in cabbage were identified. Based on the classification system described by Edstam et al. (2011) and Salminen et al. (2016), these BoLTPs could be classified into six types (1, 2, C, D, E, and G). Bioinformatic analysis predicted that most of BoLTPs are secreted proteins. In order to verify the predicted results, the bud-specific BoLTP1.7 and black rot-responsive BoLTP2.3 were selected as representative proteins for subcellular localization. The results showed that the fluorescence signals of BoLTP1.7 and BoLTP2.3 fused with GFP were detected in the extracellular environment, indicating they are 
282

283

284

286

287

288

289

290

291

292

293

294

295

296

297

298

299

300

301

302

secreted proteins (Fig. S3). Orthology analysis showed that most of the BoLTP genes have orthologous nsLTP genes in A. thaliana, indicating the cabbage nsLTP genes were derived from a common ancestor shared with $A$. thaliana. Compared with the Arabidopsis genes, the numbers of cabbage $n s L T P s$ in type 1 and $\mathrm{D}$ were expanded, while the gene numbers of the other types were reduced or unchanged. It is worth mentioning that 39 Arabidopsis nsLTP genes did not have a BoLTP ortholog. These results indicate that there are not only gene duplications and triplications but also gene loss or mutation in the evolutionary process of cabbage.

Many studies have suggested that nsLTPs participate in sexual reproduction processes, such as pollen development, pollen exine formation, and fertilization (Ariizumi et al., 2002; Chae et

al., 2009; Huang, Chen \& Huang, 2013; Edstam \& Edqvist, 2014). Promoter activity analysis has suggested that $A T 3 G 51590$ (LTP12) is specifically expressed in tapetum at the uninucleate microspore stage and the bicellular pollen stage (Ariizumi et al., 2002). The type $\mathrm{C}$ nsLTP with exclusive expression in the tapetum, AT5G52160, has been shown contribute to pollen exine formation in Arabidopsis (Huang, Chen \& Huang, 2013). In this investigation, a high number of BoLTP genes were found to be specifically or highly expressed in buds or flowers (Fig. 4A). Among these genes, BoLTP1.1 and BoLTP1.7 are orthologous to AT3G51590, and BoLTPC1 is orthologous to AT5G52160. Moreover, BoLTP1.7, BoLTP1.10, BoLTP1.18, BoLTP2.2, BoLTP2.12, and BoLTPx2 were significantly downregulated in the buds of a male sterile mutant with defective exine. Notablely, these nsLTP proteins were also significantly down-accumulated in the male sterile mutant buds (Ji et al., 2018). The results suggested that the BoLTPs specifically or highly expressed in floral organs may play an important role in the sexual 
303

304

305

306

307

308

309

310

311

312

313

314

315

316

317

318

319

320

321

322

323

reproduction progress in cabbage.

There is much evidence that nsLTPs are related to the resistance to various types of stresses, including the resistance to phytopathogens, freezing, drought, and salt (Molina \& García-Olmedo, 1997; Hincha, 2002; Jung, Kim \& Hwang, 2003; Jung, Kim \& Hwang, 2005; McLaughlin et al., 2015). Some Arabidopsis nsLTPs have been classified as pathogenesis-related PR-14 proteins, and most of them belong to the type 1 nsLTP group (Sels et al., 2008). In this study, we found that most of these pathogenesis-related Arabidopsis genes have BoLTPs orthologs in cabbage. According to recent studies, the paralogous genes AT5G59310 (AtLTP1.11) and AT5G59320 (AtLTP1.12) could negatively regulate plant immunity in Arabidopsis. The overexpression of AT5G59320 (AtLTP1.12) enhances susceptibility of Arabidopsis to virulent bacteria and reduces the resistance of Arabidopsis to avirulent bacteria (Gao et al., 2015). In contrast, the double mutant AtLTP1.11/ AtLTP1.12 showed an increased resistance to Pseudomonas (Gao et al., 2015). Similar to the orthologous genes AtLTP1.11 and AtLTP1.12, BoLTP1.8 and BoLTP1.9

showed high expression levels in blackrot-susceptible C1184 and undetectable expression levels in blackrot-resistant C1234, indicating that the high expression of these two genes may contribute to blackrot disease susceptibility in cabbage. Furthermore, an analysis of stressrelevant cis-elements in the promoter regions of the BoLTP genes was conducted. The results show that the promoters of the BoLTP genes possess at least one stress-related cis-element (Fig. 6), indicating that the BoLTPs are involved in the stress response. Given all that, the BoLTP genes identified in this study could be used to further seek stress-resistant genes in cabbage and other Brassica crops. 
genes showed significantly different expression patterns (Fig. 5). Previous studies have shown

that the alteration of expression patterns is an important indicator of functional divergence

between duplicated genes (Makova \& Li, 2003; Ganko, Meyers \& Vision, 2007; Hellsten et al., 2007). In other words, functional divergence could eliminate the redundancy of these duplicated

BoLTP genes, which may be beneficial in multiple biological processes, such as cabbage growth,

sexual reproduction and resistance to stress. However, in-depth studies should be carried out to

reveal the biological functions of the BoLTPs in the development of different organs and in

resistance to stress.

\section{CONCLUSIONS}

Eighty-nine BoLTPS were identified based on genome-wide research. These genes were

classified into six different types $(1,2, C, D, E$, and G). The tertiary structure, phylogenetic

development, and gene expression of the BoLTPs were also summarized. The expression

analysis shows the functional importance of BoLTPs in sexual reproduction and stress response.

It is important to continue to reveal the functions of these BoLTPs with basic experiments such

as overexpression or knock-down strategies followed with detailed phenotypic investigations.

Moreover, the BoLTPs identified in this study provide a reference for creation of resistant

metarials or artificial regulation of cabbage fertility by using genetic engineering technology.

\section{REFERENCES}

Ariizumi T, Amagai M, Shibata D, Hatakeyama K, Watanabe M, Toriyama K. 2002. 
protein, xyloglucan endotransglucosylase/hydrolase and polygalacturonase in transgenic Arabidopsis thaliana. Plant Cell Reports 21: 90-96 DOI 10.1007/s00299-002-0487-3.

Bailey TL, Boden M, Buske FA, Frith M, Grant CE, Clementi L, Ren J, Li WW, Noble WS. 2009. MEME SUITE: tools for motif discovery and searching. Nucleic Acids Research 37:W202-W208 DOI 10.1093/nar/gkp335.

Boutrot F, Chantret N, Gautier MF. 2008. Genome-wide analysis of the rice and Arabidopsis non-specific lipid transfer protein (nsLtp) gene families and identification of wheat nsLtp genes by EST data mining. BMC Genomics 9: 86 DOI 10.1186/1471-2164-9-86.

Carvalho AO, Gomes VM. 2007. Role of plant lipid transfer proteins in plant cell physiologyaconcise review. Peptides 28: 1144-1153 DOI 10.1016/j.peptides.2007.03.004.

Chae K, Kieslich CA, Morikis D, Kim SC, Lord EM. 2009 A gain-of-function mutation of Arabidopsis lipid transfer protein 5 disturbs pollen tube tip growth and fertilization. The Plant Cell 21: 3902-3914 DOI 10.1105/tpc.109.070854.

Cheng F, Mandakova T, Wu J, Xie Q, Lysak MA, Wang X. 2013. Deciphering the diploid ancestral genome of the mesohexaploid Brassica rapa. The Plant Cell 25: 1541-1554 DOI 10.1105/tpc.113.110486.

Debono A, Yeats TH, Rose JK, Bird D, Jetter R, Kunst L, Samuels L. 2009. Arabidopsis LTPG is a glycosylphosphatidylinositol-anchored lipid transfer protein required for export of lipids to the plant surface. The Plant Cell 21: 1230 DOI 10.1105/tpc.108.064451.

Douliez JP, Michon T, Elmorjani K, Marion D. 2000. Structure, biological and technological functions of lipid transfer proteins and indolines, the major lipid binding proteins from cereal 
366

367

368

369

370

371

372

373

374

375

376

377

378

379

380

381

382

383

384

385

386

kernels. Journal of Cereal Science 32: 1-20 DOI 10.1006/jcrs.2000.0315.

Dayho $\square$ MO, Schwartz RM, Orcutt BC. 1978. A model of evolutionary change in proteins. Atlas of Protein Sequence and Structure 5: 345-352.

Eddy SR. 2011. Accelerated profile HMM searches. Plos Computational Biology 7: e1002195 DOI 10.1371/journal.pcbi.1002195.

Edstam MM, Blomqvist K, Eklöf A, Wennergren U, Edqvist J. 2013. Coexpression patterns indicate that GPI-anchored non-specific lipid transfer proteins are involved in accumulation of cuticular wax, suberin and sporopollenin. Plant Molecular Biology 83: 625-649 DOI 10.1007/s11103-013-0113-5.

Edstam MM, Edqvist J. 2014. Involvement of GPI-anchored lipid transfer proteins in the development of seed coats and pollen in Arabidopsis thaliana. Physiologia Plantarum 152: 32 DOI 10.1111/ppl.12156.

Edstam MM, Viitanen L, Salminen TA, Edqvist J. 2011. Evolutionary History of the NonSpecific Lipid Transfer Proteins. Molecular Plant 4: 947-964 DOI 10.1093/mp/ssr019.

Eisenhaber B, Eisenhaber F. 2004. Glycosylphosphatidylinositol lipid anchoring of plant proteins. Sensitive prediction from sequence-and genome-wide studies for arabidopsis and rice. Plant Physiology 133: 1691-1701 DOI 10.1104/pp.103.023580.

Ganko EW, Meyers BC, Vision TJ. 2007. Divergence in expression between duplicated genes in Arabidopsis. Molecular Biology and Evolution 24: 2298-2309 DOI 10.1093/molbev/msm158.

Gao S, Guo W, Feng W, Liu L, Song X, Chen J, Hou W, Zhu H, Tang S, Hu J. 2015. LTP3 contributes to disease susceptibility in Arabidopsis by enhancing ABA biosynthesis. 
387

388

389

390

391

392

393

394

395

396

397

398

399

400

401

402

403

404

405

406

407

Molecular Plant Pathology 17: 412-426 DOI 10.1111/mpp.12290.

Gorjanović S, Sužnjević D, Beljanski M, Hranisavljević J. 2004. Barley lipid-transfer protein as heavy metal scavenger. Environmental Chemistry Letters 2: 113-116 DOI 10.1007/s10311004-0084-5.

Guo L, Yang H, Zhang X, Yang S. 2013. Lipid transfer protein 3 as a target of MYB96 mediates freezing and drought stress in Arabidopsis. Journal of Experimental Botany 64: 1755-1767 DOI 10.1093/jxb/ert040.

Hellsten U, Khokha MK, Grammer TC, Harland RM, Richardson P, Rokhsar DS. 2007. Accelerated gene evolution and subfunctionalization in the pseudotetraploid frog Xenopus laevis. BMC Biology 5: 1-14 DOI 10.1186/1741-7007-5-31.

Hincha DK. 2002. Cryoprotectin: a plant lipid-transfer protein homologue that stabilizes membranes during freezing. Philosophical Transactions of the Royal Society of London 357: 909 DOI 10.1098/rstb.2002.1079.

Huang MD, Chen TL, Huang AH. 2013. Abundant type III lipid transfer proteins in Arabidopsis tapetum are secreted to the locule and become a constituent of the pollen exine. Plant Physiology 163: 1218 DOI 10.1104/pp.113.225706.

Ji J, Yang L, Fang Z, Zhuang M, Zhang Y, Lv H, Liu Y, Li Z. 2018. Complementary transcriptome and proteome profiling in cabbage buds of a recessive male sterile mutant provides new insights into male reproductive development. Journal of Proteomics 179: 80-91 DOI 10.1016/j.jprot.2018.03.003.

José-Estanyol M, Gomis-Rüth FX, Puigdomènech P. 2004. The eight-cysteine motif, a versatile 
408

409

410

411

412

413

414

415

416

417

418

419

420

421

422

423

424

425

426

427

428

structure in plant proteins. Plant Physiology and Biochemistry 42: 355-365 DOI

10.1016/j.plaphy.2004.03.009.

Jung HW, Kim W, Hwang BK. 2003. Three pathogen-inducible genes encoding lipid transfer protein from pepper are differentially activated by pathogens, abiotic, and environmental stresses. Plant Cell and Environment 26: 915-928 DOI 10.1046/j.1365-3040.2003.01024.x.

Jung HW, Kim KD, Hwang BK. 2005. Identification of pathogen-responsive regions in the promoter of a pepper lipid transfer protein gene (CALTPI) and the enhanced resistance of the CALTPI transgenic Arabidopsis against pathogen and environmental stresses. Planta 221: 361-373 DOI 10.1007/s00425-004-1461-9.

Kader JC. 1996. Lipid-transfer proteins in plants. Annual Review of Plant Physiology and Plant Molecular Biology 47: 627-654 DOI 10.1146/annurev.arplant.47.1.627.

Katoh K, Standley DM. 2013. MAFFT multiple sequence alignment software version 7: improvements in performance and usability. Molecular Biology and Evolution 30: 772-780 DOI 10.1093/molbev/mst010.

Kelley LA, Mezulis S, Yates CM, Wass MN, Sternberg MJE. 2015. The Phyre2 web portal for protein modelling, prediction and analysis. Nature Protocols 10: 845-858 DOI 10.1038/nprot.2015.053.

Kiełbowiczmatuk A, Rey P, Rorat T. 2008. The organ-dependent abundance of a Solanum lipid transfer protein is up-regulated upon osmotic constraints and associated with cold acclimation ability. Journal of Experimental Botany 59: 2191-2203 DOI 10.1093/jxb/ern088. 
429

430

431

432

433

434

435

436

437

438

439

440

441

442

443

444

445

446

447

448

449

and expression analysis of the putative non-specific lipid transfer proteins in Brassica rapa L. Plos One 9: e84556 DOI 10.1371/journal.pone.0084556.

Liu S, Liu Y, Yang X, Tong C, Edwards D, Parkin LAP, Zhao M, Ma J, Yu J, Huang S, Wang X, Wang J, Lu K, Fang Z, Bancroft L, Yang T, Hu Q, Wang X, Yue Z, Li H, Yang L, Wu J, Zhou Q, Wang W, King GJ, Pires JC, Lu C, Wu Z, Sampath P, Wang Z, Guo H, Pan S, Yang L, Min J, Zhang D, Jin D, Li W, Belcram H, Tu J, Guan M, Qi C, Du D, Li J, Jiang L, Batley J, Sharpe AG, Park BS, Ruperao P, Cheng F, Waminal NE, Huang Y, Dong C, Wang L, Li J, Hu Z, Zhuang M, Huang Y, Huang J, Shi J, Mei D, Liu J, Lee TH, Wang J, Jin H, Li Z, Li X, Zhang J, Xiao L, Zhou Y, Liu Z, Liu X, Qin R, Tang X, Liu W, Wang Y, Zhang Y, Lee J, Kim HH, Denoeud HH, Xu X, Liang X, Hua W, Wang X, Wang J, Chalhoub B, Paterson AH. 2014. The Brassica oleracea genome reveals the asymmetrical evolution of polyploidgenomes. Nature Communications 5: 3930 DOI 10.1038/ncomms4930.

Liu W, Huang D, Liu K, Hu S, Yu J, Gao G, Song S. 2010. Discovery, identification and comparative analysis of non-specific lipid transfer protein (nsLtp) family in Solanaceae.

Genomics, Proteomics and Bioinformatics 8: 229-237 DOI 10.1016/S1672-0229(10)60024-1.

Makova KD, Li WH. 2003. Divergence in the spatial pattern of gene expression between human duplicate genes. Genome Research 13: 1638-1645 DOI 10.1101/gr.1133803.

Mclaughlin JE, Binumer MA, Widiez T, Finn D, McCormick S, Tumer NE. 2015. A lipid transfer protein increases the glutathione content and enhances Arabidopsis resistance to a trichothecene mycotoxin. Plos One 10: e0130204 DOI 10.1371/journal.pone.0130204.

Molina A, García-Olmedo F. 1997. Enhanced tolerance to bacterial pathogens caused by the 
450

451

452

453

454

455

456

457

458

459

460

461

462

463

464

465

466

467

468

469

470

transgenic expression of barley lipid transfer protein LTP2. Plant Journal 12: 669-675 DOI

10.1046/j.1365-313X.1997.00605.x.

Nieuwland J, Feron R, Huisman BAH, Fasolino A, Hilbers CW, Derksen J, Mariani C. 2005.

Lipid Transfer Proteins Enhance Cell Wall Extension in Tobacco. The Plant Cell 17: 20092019 DOI 10.1105/tpc.105.032094.

Petersen TN, Brunak S, Von HG, Nielsen H. 2011. SIGNALP 4.0: discriminating signal peptides from transmembrane regions. Nature Methods 8: 785 DOI 10.1038/nmeth.1701.

Ronquist F, Teslenko M, Van Der Mark P, Ayres DL, Darling A, Höhna S, Larget B, Liu L, Suchard MA, Huelsenbeck JP. 2012. MrBayes 3.2: efcient Bayesian phylogenetic inference and model choice across a large model space. Systematic Biology 61: 539-542 DOI 10.1093/sysbio/sys029.

Safi H, Saibi W, Alaoui MM, Hmyene A, Masmoudi K, Hanin M, Brini F. 2015. A wheat lipid transfer protein (TdLTP4) promotes tolerance to abiotic and biotic stress in Arabidopsis thaliana. Plant Physiology and Biochemistry 89: 64-75 DOI 10.1016/j.plaphy.2015.02.008.

Salminen TA, Blomqvist K, Edqvist J. 2016. Lipid transfer proteins: classification, nomenclature, structure, and function. Planta 244: 971-997 DOI 10.1007/s00425-016-2585-4.

Saltzmann KD, Giovanini MP, Ohm HW, Williams CE. 2010. Transcript profiles of two wheat lipid transfer protein-encoding genes are altered during attack by Hessian fly larvae. Plant Physiology \& Biochemistry 48: 54-61 DOI 10.1016/j.plaphy.2009.10.004.

Schweiger W, Steiner B, Ametz C, Siegwart G, Wiesenberger G, Berthiller F, Lemmens M, Jia H, Adam G, Muehlbauer GJ, Kreil DP, Buerstmayr H. 2013. Transcriptomic characterization 
471

472

473

474

475

476

477

478

479

480

481

482

483

484

485

486

487

488

489

490

491

of two major Fusarium resistance quantitative loci (QTLs), Fhb1 and Qfhs.ifa-5A, identifies novel candidate genes. Molecular Plant Pathology 14: 772-785 DOI 10.1111/mpp.12048.

Sels J, Mathys J, De Coninck BM, Cammue BP, De Bolle MF. 2008. Plant pathogenesis-related (PR) proteins: a focus on PR peptides. Plant Physiology and Biochemistry 46: 941-950 DOI 10.1016/j.plaphy.2008.06.011.

Sun JY, Gaudet DA, Lu ZX, Frick M, Puchalski B, Laroche A. 2008. Characterization and antifungal properties of wheat nonspecific lipid transfer proteins. Molecular Plant-Microbe Interactions 21: 346-360 DOI 10.1094/MPMI-21-3-0346.

Sparkes IA, Runions J, Kearns A, Hawes C. 2006. Rapid, transient expression of fluorescent fusion proteins in tobacco plants and generation of stably transformed plants. Nature Protocols 1: 2019-2025 DOI 10.1038/nprot.2006.286.

Wu G, Robertson AJ, Liu X, Zheng P, Wilen RW, Nesbitt NT, Gusta LV. 2004. A lipid transfer protein gene BG-14 is differentially regulated by abiotic stress, ABA, anisomycin, and sphingosine in bromegrass (Bromus inermis). Journal of Plant Physiology 161: 449-458 DOI $10.1078 / 0176-1617-01259$.

Wu Y, Feng X, Jin Y, Wu Z, Hankey W, Paisie C, Li L, Liu F, Barsky SH, Zhang W, Ganju R, Zou X. 2010. A novel mechanism of indole-3-carbinol effects on breast carcinogenesis involves induction of Cdc25A degradation. Cancer Prevention Research 3: 818 DOI 10.1158/1940-6207.CAPR-09-0213.

Yao Q, Xia E, Liu F, Gao L. 2015. Genome-wide identification and comparative expression analysis reveal a rapid expansion and functional divergence of duplicated genes in the 
492 WRKY gene family of cabbage, Brassica oleracea var. capitata. Gene 557: 35-42 DOI

$493 \quad 10.1016 /$ j.gene.2014.12.005.

494 Yu G, Hou W, Du X, Wang L, Wu H, Zhao L, Kong L, Wang H. 2014. Identification of wheat

495 non-specific lipid transfer proteins involved in chilling tolerance. Plant Cell Reports 33:

496 1757-1766 DOI 10.1007/s00299-014-1655-y.

497

Zhang D, Wengier D, Shuai B, Gui C, Muschietti J, McCormick S, Tang W. 2008. The pollen receptor kinase LePRK2 mediates growth-promoting signals and positively regulates pollen germination and tube growth. Plant Physiology 148: 1368-1379 DOI 10.1104/pp.108.124420. 
Figure 1

Circos diagram of syntenic nsLTP genes in A. thaliana and cabbage (A). Genomic localization of the BoLTP genes in the chromosomes of cabbage (B). Gene ontology categories of BoLTPS (C).

Ch1 to Ch5 are $A$. thaliana chromosomes, and $\mathrm{C} 01$ to $\mathrm{C} 10$ are cabbage chromosomes. The tandem duplication repeats is indicated by red rectangles.

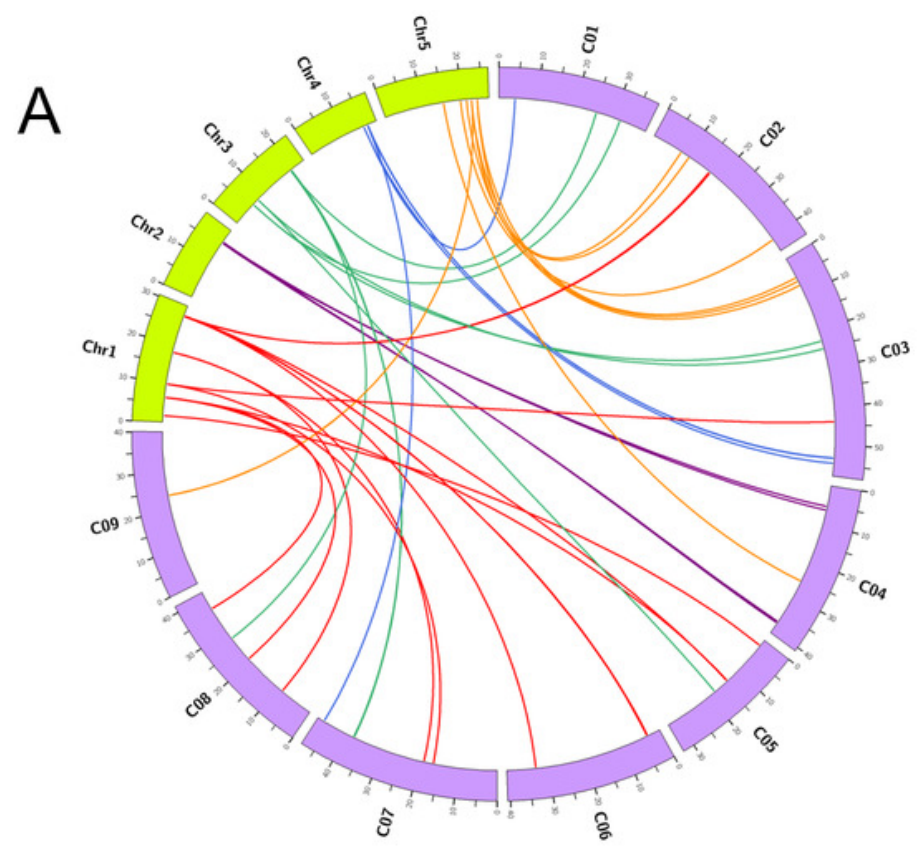

C
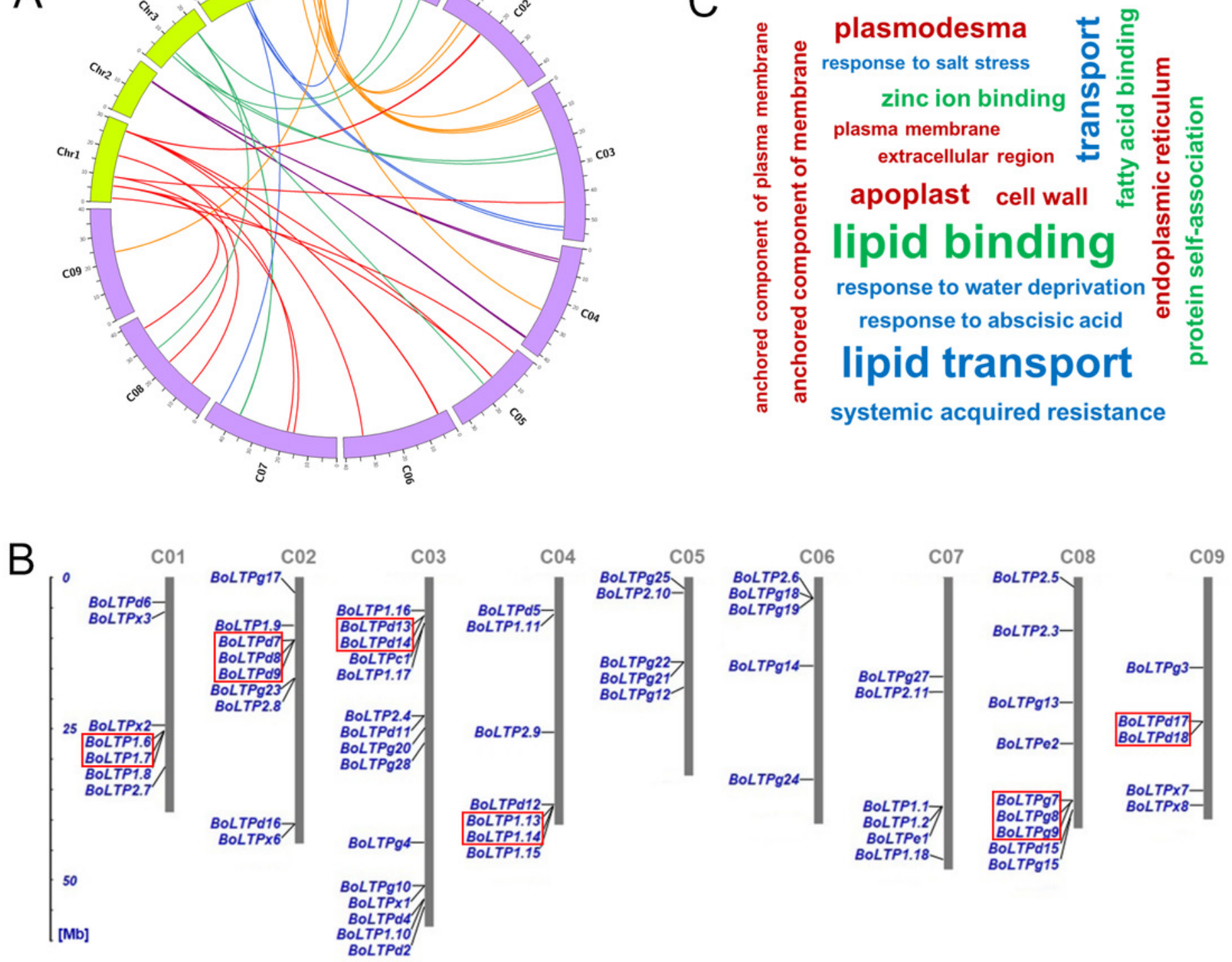
Figure 2

Schematic representation of the structure and cystein pairing pattern of BoLTP1.5 (A), BoLTP2.1 (B) and BoLTPd15 (C).

The four disulfide bonds are shown in yellow.

A
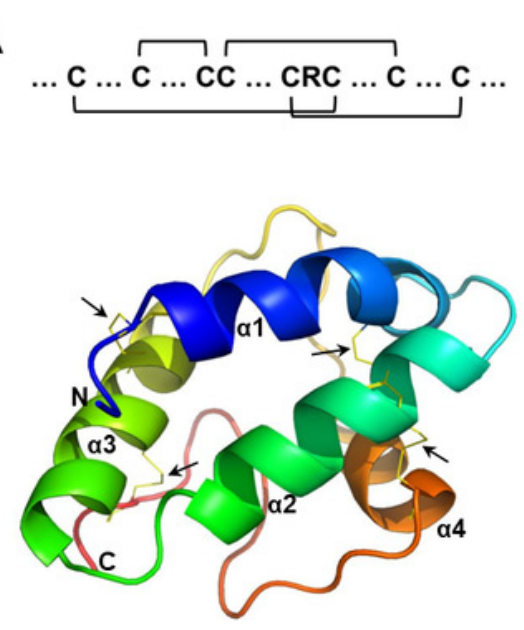

B
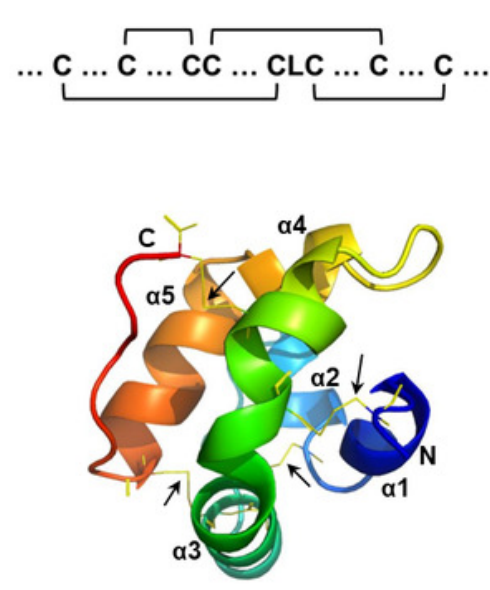

C

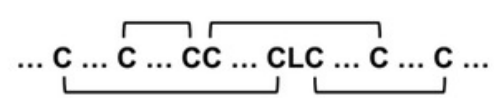

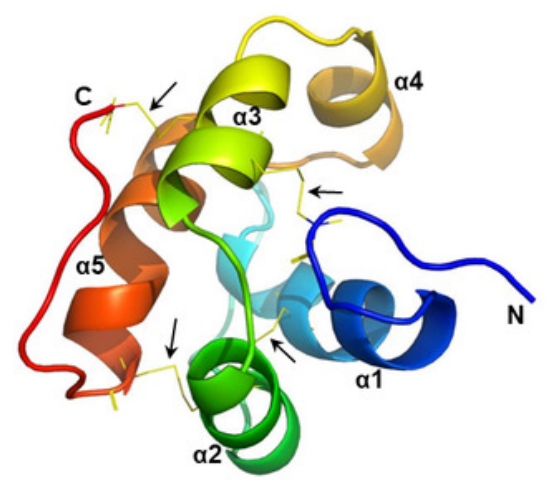




\section{Figure 3}

Phylogenetic tree of the predicted cabbage nsLTP genes and the representative members of nsLTP gene family.

Phylogenetic analysis was performed using FastTree based on the WAG+CAT model.

Different species are shown with different colors. The accession numbers of the nsLTPs are shown in Table S3. 


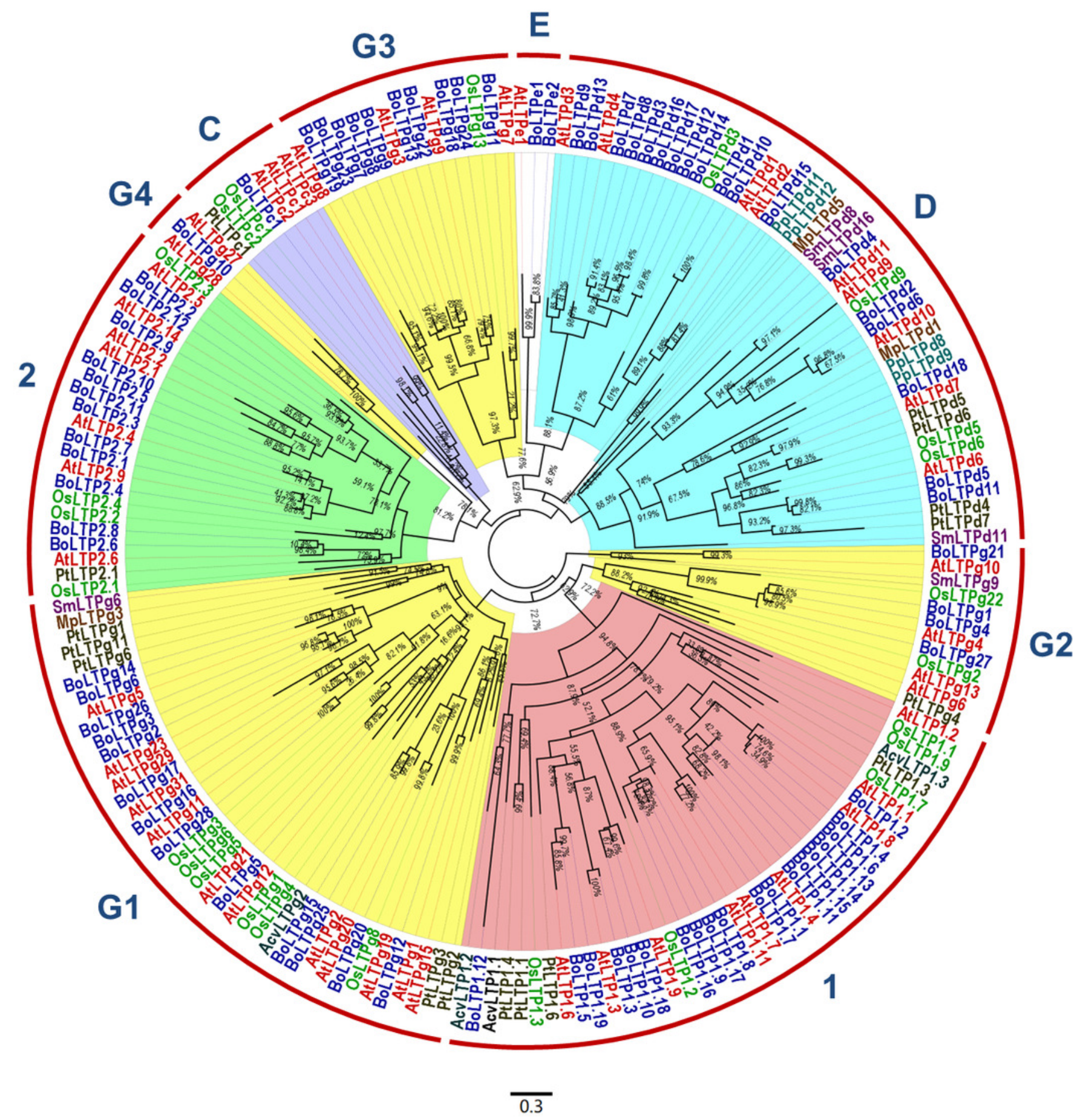




\section{Figure 4}

Expression analysis of BoLTP genes.

(A) Expression profiles of BoLTP genes in seven organs. (B, C, D) Differential expression analysis of BoLTPs in response to cold, heat and black rot disease. (E) Differential expression analysis of BoLTPs in male sterile/fertile buds. 

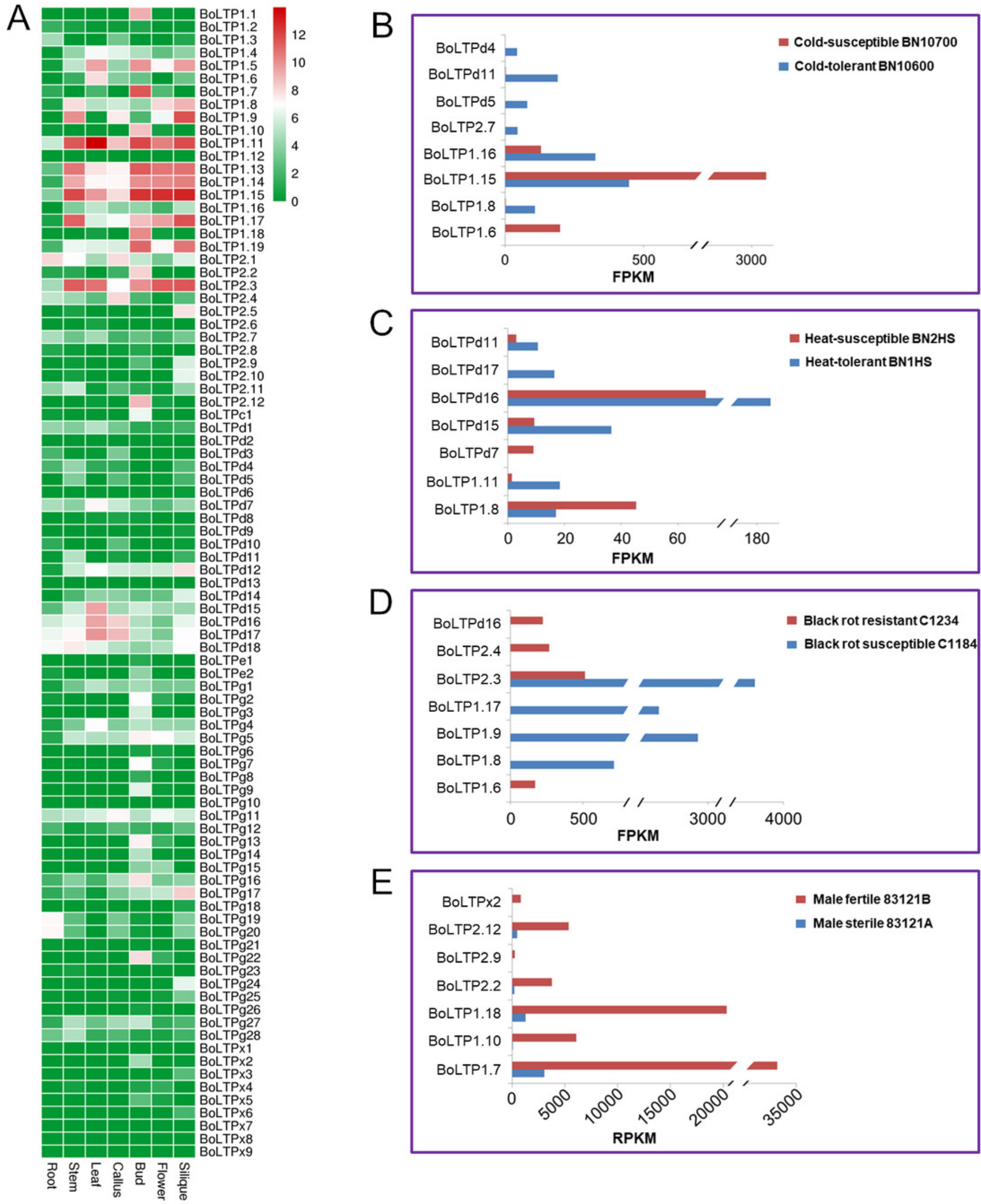
Figure 5

Different transcript levels of duplicated BoLTP genes.

The BoLTP gene expression level was measured by $\log _{2}(1+$ FPKM) value.

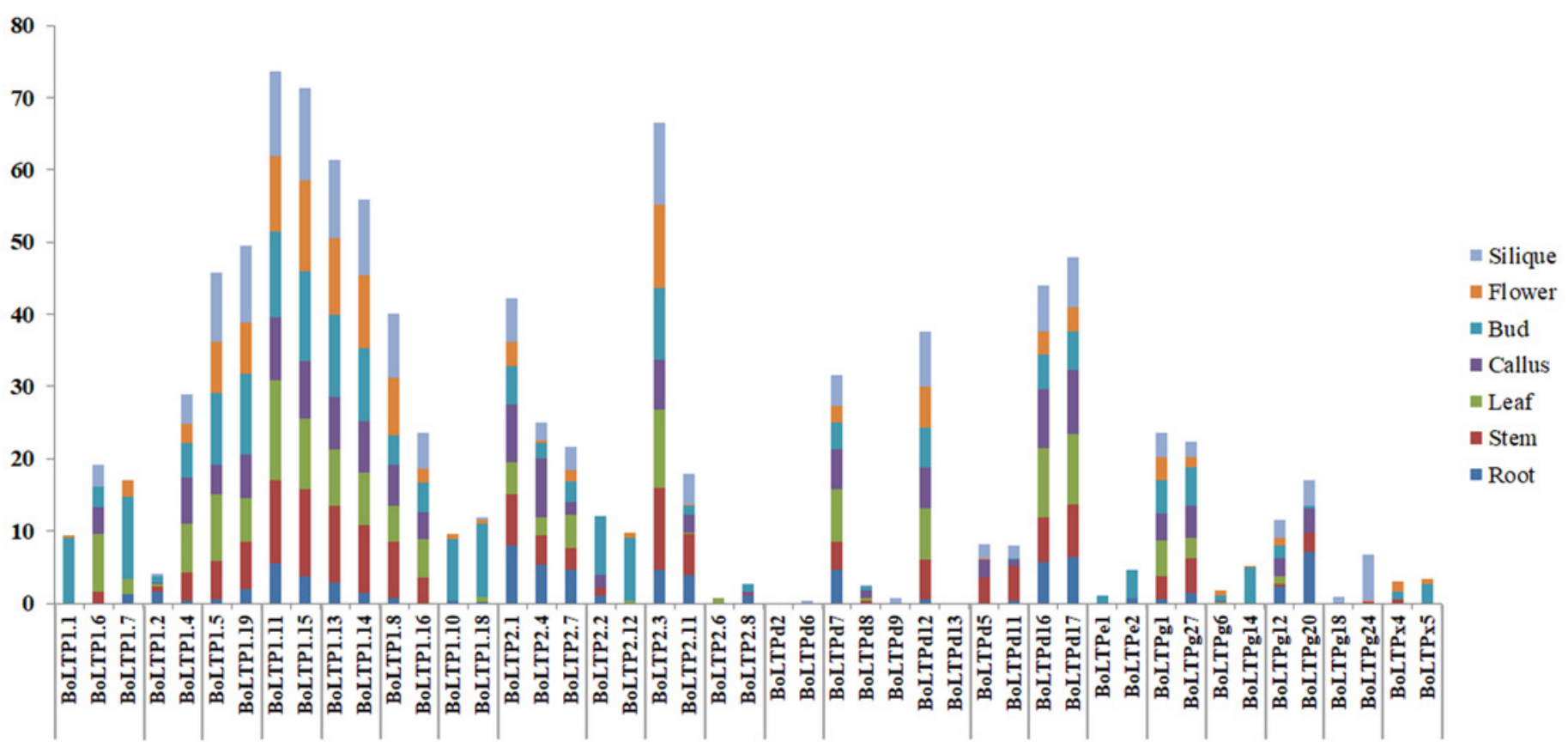




\section{Figure 6}

Summary of stress-related cis-elements in the upstream regions of BoLTP genes.

The putative cis-elements in the promoters were analyzed using PlantCARE.

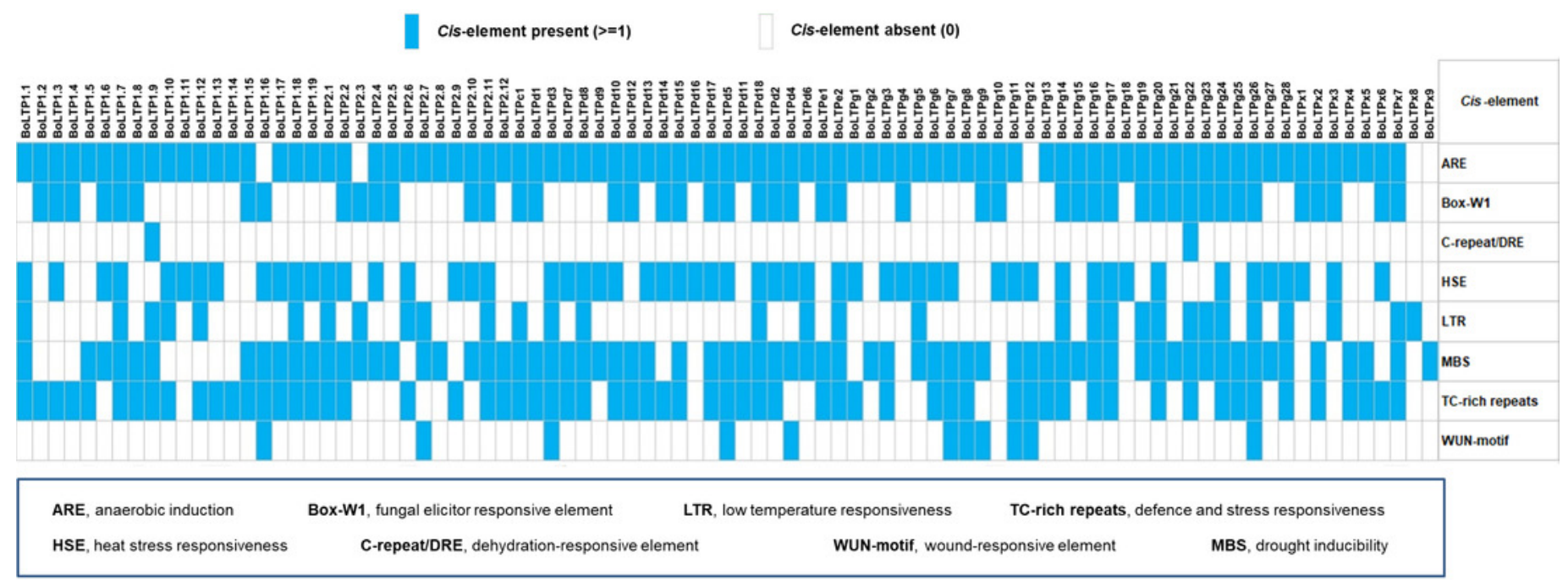




\section{Table $\mathbf{1}$ (on next page)}

The occurrence of non-specific lipid transfer proteins in cabbage, and some of their features.

a The accession numbers of BoLTPs are shown in Table S2. b Subcellular target for the protein. $\mathrm{S}=$ secretory pathway, $\mathrm{c}=$ chloroplast. $\mathbf{c}$ Position of the intron is given as the number of bases from the codon encoding the eighth cysteine in the $8 \mathrm{CM}$. 


\begin{tabular}{|c|c|c|c|c|c|c|c|}
\hline \multirow[b]{2}{*}{ Name $^{a}$} & \multicolumn{2}{|c|}{ Signal peptide } & \multicolumn{3}{|c|}{ Mature protein } & \multirow{2}{*}{$\begin{array}{c}\text { Intron } \\
\text { Amount/Position }\end{array}$} & \multirow{2}{*}{$\begin{array}{c}\text { orthologous } \\
\text { genes in } \\
\text { A. thaliana }\end{array}$} \\
\hline & $\begin{array}{c}\text { Amino } \\
\text { acids }\end{array}$ & Target $^{\mathbf{b}}$ & $\begin{array}{l}\text { Amino } \\
\text { acids }\end{array}$ & Mass (Da) & pI & & \\
\hline \multicolumn{8}{|l|}{ Type 1} \\
\hline BoLTP1.1 & 24 & s & 95 & 9922.37 & 7.40 & $1(5)$ & $\underline{\mathrm{AT} 3 \mathrm{G} 51590}$ \\
\hline BoLTP1.2 & 25 & $\mathrm{~s}$ & 91 & 9394.83 & 10.13 & 0 & AT3G51600 \\
\hline BoLTP1.3 & 24 & $\mathrm{~s}$ & 92 & 9310.59 & 7.71 & $1(5)$ & AT2G18370 \\
\hline BoLTP1.4 & 25 & $\mathrm{~s}$ & 91 & 9682.25 & 11.42 & 0 & AT3G51600 \\
\hline BoLTP1.5 & 19 & $\mathrm{~s}$ & 92 & 9549.78 & 8.51 & 0 & AT3G08770 \\
\hline BoLTP1.6 & 25 & $\mathrm{~s}$ & 91 & 9693.23 & 11.27 & 0 & $\underline{\text { AT3G51590 }}$ \\
\hline BoLTP1.7 & 24 & $\mathrm{~s}$ & 90 & 9498.97 & 8.19 & 0 & AT3G51590 \\
\hline BoLTP1.8 & 23 & $\mathrm{~s}$ & 92 & 9175.57 & 8.49 & $1(5)$ & AT5G59320 \\
\hline BoLTP1.9 & 23 & $\mathrm{~s}$ & 87 & 8723.11 & 8.70 & 0 & $\underline{\text { AT5G59310 }}$ \\
\hline BoLTP1.10 & 26 & $\mathrm{~s}$ & 136 & 14404.74 & 9.13 & $1(5)$ & $\underline{\text { AT4G33355 }}$ \\
\hline BoLTP1.11 & 18 & s & 116 & 11905.88 & 9.37 & 0 & $\underline{\mathrm{AT} 2 \mathrm{G} 38540}$ \\
\hline BoLTP1.12 & 22 & $\mathrm{~s}$ & 96 & 10212.54 & 3.63 & 0 & AT5G62065 \\
\hline BoLTP1.13 & 25 & $\mathrm{~s}$ & 94 & 9590.03 & 9.08 & 0 & $\underline{\mathrm{AT} 2 \mathrm{G} 38530}$ \\
\hline BoLTP1.14 & 25 & $\mathrm{~s}$ & 94 & 9590.03 & 9.08 & 0 & AT2G38530 \\
\hline BoLTP1.15 & 25 & $\mathrm{~s}$ & 94 & 9520.92 & 8.91 & 0 & $\underline{\mathrm{AT} 2 \mathrm{G} 38540}$ \\
\hline BoLTP1.16 & 23 & $\mathrm{~s}$ & 100 & 10493.99 & 8.70 & $1(5)$ & $\underline{\text { AT5G59320 }}$ \\
\hline BoLTP1.17 & 23 & $\mathrm{~s}$ & 87 & 8792.32 & 9.03 & 0 & \\
\hline BoLTP1.18 & 21 & $\mathrm{~s}$ & 97 & 10061.41 & 7.69 & $1(5)$ & $\underline{\text { AT4G33355 }}$ \\
\hline BoLTP1.19 & 20 & $\mathrm{~s}$ & 93 & 9648.84 & 8.73 & 0 & AT3G08770 \\
\hline \multicolumn{8}{|l|}{ Type 2} \\
\hline BoLTP2.1 & 28 & $\mathrm{~s}$ & 68 & 7411.84 & 9.75 & 0 & AT3G18280 \\
\hline BoLTP2.2 & 20 & $\mathrm{~s}$ & 76 & 7716.91 & 8.20 & 0 & AT1G66850 \\
\hline BoLTP2.3 & 29 & $\mathrm{~s}$ & 68 & 7143.28 & 8.90 & 0 & $\underline{\mathrm{AT} 1 \mathrm{G} 48750}$ \\
\hline BoLTP2.4 & 28 & s & 68 & 7381.78 & 9.54 & 0 & $\underline{\mathrm{AT} 3 \mathrm{G} 18280}$ \\
\hline BoLTP2.5 & 24 & s & 73 & 7877.10 & 4.80 & 0 & AT3G57310 \\
\hline BoLTP2.6 & 30 & $\mathrm{~s}$ & 67 & 7636.89 & 8.17 & 0 & $\underline{\mathrm{AT} 1 \mathrm{G} 73780}$ \\
\hline BoLTP2.7 & 28 & $\mathrm{~s}$ & 68 & 7460.87 & 9.94 & 0 & AT3G18280 \\
\hline BoLTP2.8 & 30 & $\mathrm{~s}$ & 68 & 7645.89 & 8.42 & 0 & $\underline{\mathrm{AT} 1 \mathrm{G} 73780}$ \\
\hline BoLTP2.9 & 24 & $\mathrm{~s}$ & 78 & 8524.93 & 5.18 & 0 & $\underline{\text { AT5G38195 }}$ \\
\hline BoLTP2.10 & 24 & $\mathrm{~s}$ & 75 & 7792.09 & 7.44 & 0 & \\
\hline BoLTP2.11 & 29 & $\mathrm{~s}$ & 68 & 7255.47 & 9.06 & 0 & $\underline{\mathrm{AT} 1 \mathrm{G} 48750}$ \\
\hline BoLTP2.12 & 21 & $\mathrm{~s}$ & 74 & 7647.76 & 7.71 & 0 & AT1G66850 \\
\hline \multicolumn{8}{|l|}{ Type C } \\
\hline BoLTPc1 & 34 & $\mathrm{~s}$ & 64 & 6729.72 & 6.71 & 0 & AT5G52160 \\
\hline
\end{tabular}

Type D 


\begin{tabular}{|c|c|c|c|c|c|c|c|}
\hline BoLTPd1 & 23 & $\mathrm{~s}$ & 78 & 8281.64 & 8.19 & 0 & \\
\hline BoLTPd2 & 19 & $\mathrm{~s}$ & 89 & 9521.31 & 9.15 & $1(4)$ & $\underline{\mathrm{AT} 4 \mathrm{G} 30880}$ \\
\hline BoLTPd3 & 28 & $\mathrm{~s}$ & 87 & 9234.97 & 9.30 & 0 & \\
\hline BoLTPd4 & 28 & $\mathrm{~s}$ & 86 & 9285.70 & 8.86 & $1(4)$ & $\underline{\mathrm{AT} 4 \mathrm{G} 33550}$ \\
\hline BoLTPd5 & 23 & $\mathrm{~s}$ & 92 & 9521.52 & 10.48 & $1(4)$ & $\underline{\mathrm{AT} 2 \mathrm{G} 37870}$ \\
\hline BoLTPd6 & 19 & $\mathrm{~s}$ & 90 & 9607.40 & 8.71 & $1(4)$ & $\underline{\mathrm{AT} 4 \mathrm{G} 30880}$ \\
\hline BoLTPd7 & 28 & $\mathrm{~s}$ & 84 & 8910.50 & 8.72 & 0 & $\underline{\mathrm{AT} 5 \mathrm{G} 55450}$ \\
\hline BoLTPd8 & 28 & $\mathrm{~s}$ & 87 & 9204.80 & 8.50 & 0 & $\underline{\mathrm{AT} 5 \mathrm{G} 55450}$ \\
\hline BoLTPd9 & 28 & $\mathrm{~S}$ & 90 & 9616.54 & 9.06 & $1(4)$ & $\underline{\text { AT5G55450 }}$ \\
\hline BoLTPd10 & 23 & $\mathrm{~s}$ & 78 & 8348.74 & 8.68 & 0 & \\
\hline BoLTPd11 & 23 & $\mathrm{~s}$ & 92 & 9517.49 & 10.42 & $1(4)$ & $\underline{\mathrm{AT} 2 \mathrm{G} 37870}$ \\
\hline BoLTPd12 & 26 & $\mathrm{~s}$ & 73 & 7445.50 & 4.46 & 0 & $\underline{\mathrm{AT} 5 \mathrm{G} 55450}$ \\
\hline BoLTPd13 & 30 & $\mathrm{~s}$ & 89 & 9707.56 & 8.80 & 0 & $\underline{\mathrm{AT} 5 \mathrm{G} 55450}$ \\
\hline BoLTPd14 & 26 & $\mathrm{~s}$ & 73 & 7521.59 & 4.46 & 0 & \\
\hline BoLTPd15 & 27 & $\mathrm{~s}$ & 76 & 8139.38 & 5.04 & 0 & $\underline{\mathrm{AT} 5 \mathrm{G} 48490}$ \\
\hline BoLTPd16 & 28 & $\mathrm{~s}$ & 79 & 8381.89 & 9.03 & $1(4)$ & $\underline{\text { AT5G55410 }}$ \\
\hline BoLTPd17 & 28 & $\mathrm{~s}$ & 74 & 7756.12 & 8.88 & 0 & $\underline{\mathrm{AT} 5 \mathrm{G} 55410}$ \\
\hline BoLTPd18 & 23 & $\mathrm{~s}$ & 91 & 9356.81 & 8.70 & $1(4)$ & AT3G53980 \\
\hline \multicolumn{8}{|l|}{ Type E } \\
\hline BoLTPe1 & 24 & $\mathrm{c}$ & 97 & 10408.26 & 4.72 & 0 & $\underline{\mathrm{AT} 3 \mathrm{G} 52130}$ \\
\hline BoLTPe2 & 25 & $\mathrm{~s}$ & 97 & 10290.02 & 4.72 & 0 & $\underline{\mathrm{AT} 3 \mathrm{G} 52130}$ \\
\hline \multicolumn{8}{|l|}{ Type G } \\
\hline BoLTPg1 & 21 & $\mathrm{~s}$ & 173 & 17684.24 & 5.64 & $1(4)$ & AT1G27950 \\
\hline BoLTPg2 & 22 & $\mathrm{~s}$ & 185 & 18970.72 & 8.45 & $2(1,155)$ & AT4G08670 \\
\hline BoLTPg3 & 22 & $\mathrm{c}$ & 181 & 18590.24 & 7.70 & $2(1,134)$ & \\
\hline BoLTPg4 & 21 & $\mathrm{~s}$ & 174 & 17641.27 & 6.11 & $1(4)$ & $\underline{\mathrm{AT} 1 \mathrm{G} 27950}$ \\
\hline BoLTPg5 & 17 & $\mathrm{~s}$ & 173 & 17386.80 & 4.31 & $2(4,926)$ & AT3G43720 \\
\hline BoLTPg6 & 19 & $\mathrm{~s}$ & 285 & 29369.39 & 4.70 & $2(1,147)$ & $\underline{\mathrm{AT} 1 \mathrm{G} 36150}$ \\
\hline BoLTPg7 & 19 & $\mathrm{~s}$ & 160 & 15708.96 & 8.14 & $2(19,167)$ & $\underline{\mathrm{AT} 1 \mathrm{G} 18280}$ \\
\hline BoLTPg8 & 22 & $\mathrm{~s}$ & 136 & 13860.91 & 5.59 & $1(19)$ & $\underline{\mathrm{AT} 1 \mathrm{G} 18280}$ \\
\hline BoLTPg9 & 22 & $\mathrm{~s}$ & 160 & 15697.94 & 7.73 & $2(19,167)$ & $\underline{\mathrm{AT} 1 \mathrm{G} 18280}$ \\
\hline BoLTPg10 & 31 & $\mathrm{~s}$ & 157 & 16414.03 & 4.68 & $1(19)$ & $\underline{\mathrm{AT} 4 \mathrm{G} 22666}$ \\
\hline BoLTPg11 & 25 & $\mathrm{~s}$ & 124 & 12877.69 & 6.30 & $2(4,126)$ & AT1G62790 \\
\hline BoLTPg12 & 24 & $\mathrm{~s}$ & 147 & 14871.51 & 5.05 & $2(7,140)$ & $\underline{\mathrm{AT} 3 \mathrm{G} 22600}$ \\
\hline BoLTPg13 & 20 & $\mathrm{~s}$ & 155 & 15572.72 & 6.07 & $2(-5,40)$ & $\underline{\mathrm{AT} 1 \mathrm{G} 18280}$ \\
\hline BoLTPg14 & 19 & $\mathrm{~s}$ & 190 & 19568.39 & 5.19 & $1(1)$ & AT1G36150 \\
\hline BoLTPg15 & 26 & $\mathrm{~s}$ & 178 & 18208.64 & 4.34 & $4(4,164,371,617)$ & $\underline{\mathrm{AT} 1 \mathrm{G} 05450}$ \\
\hline BoLTPg16 & 25 & $\mathrm{~s}$ & 154 & 15227.71 & 7.11 & $2(4,211)$ & \\
\hline BoLTPg17 & 24 & $\mathrm{~s}$ & 148 & 14812.25 & 8.48 & $2(4,289)$ & \\
\hline BoLTPg18 & 22 & $\mathrm{~s}$ & 90 & 9701.35 & 6.99 & $1(13)$ & $\underline{\mathrm{AT} 1 \mathrm{G} 73560}$ \\
\hline BoLTPg19 & 21 & $\mathrm{~s}$ & 116 & 12333.19 & 5.42 & $1(7)$ & $\underline{\mathrm{AT} 1 \mathrm{G} 73550}$ \\
\hline
\end{tabular}




\begin{tabular}{|c|c|c|c|c|c|c|c|}
\hline BoLTPg20 & 23 & $\mathrm{~s}$ & 182 & 18472.01 & 4.99 & $1(31)$ & AT3G22620 \\
\hline BoLTPg21 & 26 & $\mathrm{~s}$ & 162 & 16361.87 & 8.73 & $2(7,188)$ & AT1G73890 \\
\hline BoLTPg22 & 22 & $\mathrm{~s}$ & 158 & 15803.06 & 6.93 & $2(13,173)$ & AT1G18280 \\
\hline BoLTPg23 & 21 & $\mathrm{~s}$ & 127 & 13708.39 & 4.18 & $2(13,193)$ & $\underline{\mathrm{AT} 1 \mathrm{G} 73550}$ \\
\hline BoLTPg24 & 22 & $\mathrm{~s}$ & 127 & 13220.35 & 5.62 & $2(13,163)$ & $\underline{\text { AT1G73560 }}$ \\
\hline BoLTPg25 & 26 & $\mathrm{~s}$ & 175 & 17570.14 & 5.66 & $2(4,173,410,623)$ & $\underline{\mathrm{AT} 1 \mathrm{G} 05450}$ \\
\hline BoLTPg26 & 22 & $\mathrm{c}$ & 179 & 18303.98 & 8.45 & $2(1,131)$ & \\
\hline BoLTPg27 & 21 & $\mathrm{~s}$ & 174 & 17769.26 & 6.90 & $1(4)$ & $\underline{\mathrm{AT} 1 \mathrm{G} 27950}$ \\
\hline BoLTPg28 & 27 & $\mathrm{~s}$ & 147 & 14350.26 & 4.69 & $2(4,126)$ & AT2G13820 \\
\hline \multicolumn{8}{|l|}{ Type X } \\
\hline BoLTPx1 & 25 & $\mathrm{~s}$ & 99 & 10667.26 & 4.57 & 0 & \\
\hline BoLTPx2 & 22 & $\mathrm{~s}$ & 95 & 10049.59 & 8.15 & 0 & \\
\hline BoLTPx3 & 23 & $\mathrm{~s}$ & 118 & 13635.59 & 5.76 & $1(1)$ & AT1G52415 \\
\hline BoLTPx4 & 24 & $\mathrm{~s}$ & 76 & 8355.81 & 8.70 & 0 & AT1G64235 \\
\hline BoLTPx 5 & 24 & $\mathrm{~s}$ & 68 & 7128.46 & 9.05 & 0 & AT1G64235 \\
\hline BoLTPx6 & 22 & $\mathrm{~s}$ & 92 & 10068.84 & 8.68 & 0 & AT4G08530 \\
\hline BoLTPx7 & 28 & $\mathrm{~s}$ & 106 & 11759.57 & 6.09 & $1(12)$ & \\
\hline BoLTPx 8 & 24 & $\mathrm{~s}$ & 96 & 10034.94 & 7.67 & 0 & \\
\hline BoLTPx9 & 21 & $\mathrm{~s}$ & 101 & 10653.27 & 7.71 & 0 & \\
\hline
\end{tabular}




\section{Table 2 (on next page)}

Some characteristics for the different types of non-specific lipid transfer proteins found in cabbage

Character " $X$ " represents any amino acid, and the Arabic numeral following " $X$ " stands for the numbers of amino acid esidues. 


\begin{tabular}{|c|c|c|c|c|c|c|c|c|c|c|}
\hline Type & GPI-anchored & & & & $\operatorname{acing} \mathbf{p}$ & ern & & & & \\
\hline 1 & No & $\mathrm{C} \mathrm{X}_{9}$ & $\mathrm{C} \quad \mathrm{X}_{13,14,16}$ & $\mathrm{CC}$ & $\mathrm{X}_{19}$ & $\mathrm{CXC}$ & $\mathrm{X}_{19,21,22,23,24}$ & $\mathrm{C}$ & $\mathrm{X}_{13}$ & $\mathrm{C}$ \\
\hline 2 & No & $\mathrm{C} \mathrm{X}_{7}$ & $\mathrm{C} \mathrm{X}_{13}$ & $\mathrm{CC}$ & $\mathrm{X}_{8}$ & $\mathrm{CXC}$ & $\mathrm{X}_{23}$ & $\mathrm{C}$ & $\mathrm{X}_{5,6}$ & $\mathrm{C}$ \\
\hline $\mathrm{C}$ & No & $\mathrm{C} \quad \mathrm{X}_{9}$ & $\mathrm{C} \quad \mathrm{X}_{16}$ & $\mathrm{CC}$ & $\mathrm{X}_{9}$ & $\mathrm{CXC}$ & $\mathrm{X}_{12}$ & $\mathrm{C}$ & $\mathrm{X}_{6}$ & $\mathrm{C}$ \\
\hline $\mathrm{D}$ & No & $\mathrm{C} \quad \mathrm{X}_{9,10,14}$ & C $X_{14,15,16,17,19}$ & $\mathrm{CC}$ & $\mathrm{X}_{9,11,12}$ & $\mathrm{CXC}$ & $\mathrm{X}_{19,22,24}$ & $\mathrm{C}$ & $\mathrm{X}_{6,7,8,9,10}$ & $\mathrm{C}$ \\
\hline $\mathrm{E}$ & No & $\mathrm{C} \mathrm{X}_{13}$ & C $\mathrm{X}_{15}$ & $\mathrm{CC}$ & $\mathrm{X}_{9}$ & $\mathrm{CXC}$ & $\mathrm{X}_{22}$ & & $\mathrm{X}_{6}$ & $\mathrm{C}$ \\
\hline G & Yes & C $\mathrm{X}_{6,9,10}$ & C $X_{11,13,14,16,17,18}$ & $\mathrm{CC}$ & $\mathrm{X}_{12}$ & $\mathrm{CXC}$ & $X_{23,24,25,26,29}$ & $\mathrm{C}$ & $X_{5,7,8,9}$ & $\mathrm{C}$ \\
\hline
\end{tabular}

2 